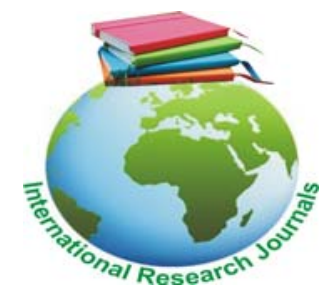

African Journal of Food Science and Technology ((ISSN: 2141-5455) Vol. 6(1) pp. 28-34, January, 2015

DOI: http:/dx.doi.org/10.14303/ajfst.2015.010

Available online @http://www.interesjournals.org/AJFST

Copyright @2015 International Research Journals

Full Length Research Paper

\title{
Physical properties of extruded snacks enriched with soybean and moringa leaf powder
}

\author{
Leonard M.P. Rweyemamu, AthumaniYusuph, Godwill D. Mrema
}

Department of Chemical and Mining Engineering, College of Engineering and Technology, University of Dar es Salaam, P. O. Box 35131, Dar es Salaam, Tanzania.

*Corresponding author email address: leo rwey@uccmail.co.tz

Abstract

This study was conducted to investigate the application of extrusion cooking in the production of snacks containing soybean (SB) and Moringa oleifera (MO) leaves as inexpensive sources of micronutrients. The specific objectives were to examine effects of barrel temperature, residence time and moisture content of feed on selected physical properties of extruded snacks (extrudates), namely water absorption index (WAI), water solubility index (WSI) and expansion ratio (ER). The extrudates were obtained by blending different levels of input ingredients of maize flour (MF) (55 to 80\%), full fat soybean flour (FFSF) (10 to 30\%), and Moringa oleifera leaf powder (MOLP) (5 to 15\%). Extrusion process variables in a twin-screw extruder were at three levels for temperature $\left(100,130\right.$ and $\left.160^{\circ} \mathrm{C}\right)$, feed moisture content $(15,22.5$ and 30\%), and residence time $(60,75$ and 90 s). The performed study revealed that the level of incorporation of both FFSF and MOLP, and feed moisture content have significant effects on the expansion ratio, water solubility index and water absorption index of the extrudates. It was concluded that the role of processing conditions and blending levels have a significant contribution to the quality characteristics of the soy-moringa expanded snacks.

Keywords: Moringa oleifera leaf powder, full-fat soybean flour, soy-moringa extrudates, extrusion cooking, surface response method

\section{INTRODUCTION}

Because of their high nutrient density, soybean (SB) and moringa oleifera (MO) have been increasingly researched as inexpensive and sustainable solutions for combating micronutrient deficiency, especially in developing countries (Malema, 2006; Joshi et al., 2010; Khan and Ghutta, 2010). One of the methods to increase the consumption of SB and $\mathrm{MO}$ is the production of expanded snacks and instant flours by using extrusion cooking, the technology which has capability to modify physicochemical properties of food components by application of pressure and high temperature at very short time(Shls, et al., 2005; Guy 2001; Liu, 1999; Alonso et al., 2001).In extrusion cooking the product quality can vary considerably depending on the extruder type, screw configuration, feed moisture, temperature profile in the barrel, screw speed, feed rate and die geometry. The results of extrusion are gelatinization of starch, denaturation of proteins, inactivation of enzymes and anti-nutritional factors, reduction of microbial counts, and improvement in digestibility and biological value of proteins (Riaz, 2007). Incorporation of MOLP in the combination of biopolymers of starch and proteins, may complicate the transformations during extrusion into expanded structure, thereby leading to processing difficulties, and may also be detrimental to key quality parameters in snacks (Liu et al., 2011). The suitability of extruded foods for a particular application depends on their functional properties like water absorption index (WAI) and water solubility index (WSI), expansion index (expansion ratio) (ER), bulk density and viscosity of the dough (Hernandez-Diaz et al., 2007). The wide variation of WAI, WSI, and ER values of extruded food products makes their utilization difficult in food process applications (Oikonomou et al., 2012).

The objectives of this work were to study the effects of barrel temperature, feed composition, feed moisture and re 
tention time (screw speed) on WAI, WSI, and ERof extruded snacks from the flour containing maize, soybean and moringa oleifera leaf by using response surface methodology (RSM).These functional properties are linked to the estimation of the behaviour of the material if further processed for use as a binder, a stabilizer, or a source of protein in beverages, health and nutrition bars, dairy, baked, and emulsified/ground meat food systems.

\section{MATERIALS AND METHODS}

\section{Full fat SB flour preparation}

The soybeans (SB) were purchased from the whole sale grain vendors at local market. The preparation of SB involved sorting, blanching, de-hulling, drying and milling. Blanching was for 3 min into a heating medium of greater than 1:10 soybeans to water ratio (water boiling at $99 \pm 1^{\circ} \mathrm{C}$ ), whereas sun drying at temperature ranging from of 29 to $32^{\circ} \mathrm{C}$ and relative humidity of 75 to $80 \%$ to a final moisture content of $10-11 \%$ was applied. Dehulleddry soybeans were milled using the hammer mill with a $300 \mu \mathrm{m}$ screen to produce FFSF.

\section{MO leaf powder preparation}

Fresh mature MO leaves were carefully harvested from a Moringa farm in the outskirts of Dar es Salaam. The leaves were washed by clean water at 1:5 leaves to water ratio to remove dusts and pests, and subsequently drainedon the draining table for about one hour to before taking them to the drying sheets inside a ventilated room at ambient temperature of 29 to $32^{\circ} \mathrm{C}$ and relative humidity of 75 to $80 \%$ and dried for 2 to 4 days to reach 11 to $12 \%$ moisture content.Dried leaves were milled using the hammer mill with a $150 \mu \mathrm{m}$ screen. Obtained MOLP was stored in airtight packages (plastic bags LDPE) which also protect the leaves from ultra-violet light to preserve nutrients.

\section{Maize flour Preparation}

Maize was purchased from the local whole sale grains vendor. The sample materials were sorted out to remove any foreign materials and damaged grains. Maize was washed to remove dusts from the sample then was sun dried for one day. The dried grain was milled using the hammer mill equipped with a $300 \mu \mathrm{m}$ screen. MF were then stored in airtight plastic bags and placed in a dry place with limited visible light.

\section{Blend preparations and moisture adjustment}

MF, FFSF and MOLP were mixed at various weight ratios, and the total moisture contents of the blends ad justed to the desired values with a hand as described by Zasypkin and Tung-Ching (1998). Weights of the components to be mixed were calculated using the following formulas as explained by Zasypkin and Tung-Ching Lee (1998):

$$
\begin{aligned}
\mathrm{C}_{\mathrm{FFSF}} & =\frac{\left[\mathrm{R}_{\mathrm{FFSF}} \times \mathrm{M} \times(100-\mathrm{X})\right]}{\left[100 \times\left(100-\mathrm{X}_{\mathrm{FFSF}}\right)\right]} \\
\mathrm{C}_{M F} & =\frac{\left[R_{M F} \times M(100-X)\right]}{\left[100 \times\left(100-X_{M F}\right)\right]} \\
\mathrm{C}_{\mathrm{MOLP}} & =\frac{\left[\mathrm{R}_{\mathrm{MOLP}} \times \mathrm{M}(100-\mathrm{X})\right]}{\left[100 \times\left(100-\mathrm{X}_{\mathrm{MOLPF}}\right)\right]} \\
W= & M-C_{F F S F}-C_{M O L P}-C_{M F}
\end{aligned}
$$

Where $\mathrm{C}_{\mathrm{FFSF}}, \mathrm{C}_{\mathrm{MOLP}}$ and $\mathrm{C}_{\mathrm{MF}}$ are the masses of FFSF, MOLP or MF respectively, $R_{F F S F}, R_{M O L P}$ and $R_{M F}$ are percentages of FFSF, MOLP or MF respectively in the blend, dry basis.

$\left(R_{F F S F}+R_{M O L P}+R_{M F}=100 \%\right) ; M$ is the total mass of the blend; $\mathrm{X}$, the moisture content of the final blend, percentage wet weight basis (w.w.b.); $W$ is the weight of water added; and $\mathrm{X}_{\mathrm{FFSF}} \mathrm{X}_{\mathrm{MOLP}}$ and $\mathrm{X}_{\mathrm{MF}}$ are the moisture contents of FFSF, MOLP or MF respectively.

\section{Extrusion cooking process}

All extruded products were made by using a twin-screw extruder (Quitong-Kneader Model JS-60D). During extrusion, samples were extruded as straight rope. The material was fed at a rate at $10 \mathrm{~kg} / \mathrm{h}$ during extrusion of all runs. Extruded samples were collected steady states extrusion conditions. Collected samples were sealed in plastic bags at ambient conditions $\left(29 \pm 1^{\circ} \mathrm{C}\right)$. The products were then stored at room temperature $\left(28-32^{\circ} \mathrm{C}\right)$ in dry place for later analysis. The measurement of diameter and length for extruded samples were taken after coolingthe extrudates for 10 minutes at room temperature.

\section{Experimental design and statistical analysis}

Combined design was used to investigate the relationships between the process variables, mixture components and response variables. A D-optimal design was used for the designing of the experiment with three independent process variables and three dependent mixture components using a statistical package. Three independent process variables including feed moisture content, barrel temperature and residence time was coded as shown in Table 1.

Dependent mixture components having MF (55-80\%), FFSF (10-30\%) and MOLP (5-15\%) was used. According to the Design Expert Version DX 7.0.0.1, a total of 36 runs from 10 formulations as shown in Table 2 were studied using response surface method to investigate the effect of the process and mixture 
30 Afr. J. Food Sci. Technol.

Table 1. A coded level of independent process variables

\begin{tabular}{llll}
\hline Variables & \multicolumn{3}{c}{ Coded levels } \\
\cline { 2 - 4 } & -1 & 0 & 1 \\
\hline Barrel temperature $\left({ }^{\circ} \mathrm{C}\right)$ & 100 & 130 & 160 \\
Feed moisture content $(\%)$ & 15 & 22.5 & 30 \\
Residence time $(\mathrm{s})$ & 60 & 75 & 90 \\
\hline
\end{tabular}

Table2. Blend formulations in extrusion experiments

\begin{tabular}{|c|c|c|c|}
\hline \multicolumn{4}{|c|}{ Blend formulations (\%) } \\
\hline & MF & MOLP & FFSF \\
\hline 1 & 60 & 30 & 10 \\
\hline 2 & 80 & 15 & 5 \\
\hline 3 & 55 & 30 & 15 \\
\hline 4 & 71 & 19 & 10 \\
\hline 5 & 80 & 12.5 & 7.5 \\
\hline 6 & 80 & 10 & 10 \\
\hline 7 & 65 & 20 & 15 \\
\hline 8 & 65 & 30 & 5 \\
\hline 9 & 75 & 10 & 15 \\
\hline 10 & 77.5 & 10 & 12.5 \\
\hline
\end{tabular}

component variables on response variables. Responses variable examined were expansion ratio, water solubility index, water absorption index and content level of vitamin $\mathrm{A}$ and iron.

\section{Determination of product physical properties}

\section{Expansionratio}

Sample products were extruded as a piece of different length from extruder. The diameter of the extrudates was measured by a Verniercalliper having $0.05 \mathrm{~mm}$ accuracy. A mean value of diameter of 5 measurements was recorded for each experimental run. The expansion ratio is defined as the ratio of the diameter of the extrudate to the diameter of the die hole. Therefore expansion ratio was calculated as the diameter of the extrudate divided by the diameter of the die as in equation 5 .

$$
\text { Expansion ratio }(E R)=\frac{D_{e}^{2}}{D_{d}^{2}}
$$

Where: $D_{e}=$ Diameter of extrudate; $D_{d}=$ Diameter of die

\section{Water absorption index (WAI) and water solubility in- $\operatorname{dex}(W S I)$}

WAI and WSI of the extruded products were determined according to Anderson et al. (1969). The extrudates were ground to fine powder of particle size approximately 250 $\mu \mathrm{m}$ using a laboratory hammer mill. Sample of about $1.25 \mathrm{~g}$ was weighed and placed in about $40 \mathrm{ml}$ centrifuge tube and suspended in $15 \mathrm{ml}$ distilled water. The sample was incubated by using a shaker at about room temperature for 30 minutes and was centrifuged at $3000 \mathrm{~g}$ for 5 minutes. The supernatant was decanted carefully into the pre-dried evaporation dish (dried at $105^{\circ} \mathrm{C}$ for $24 \mathrm{~h}$ ) with known weight. Mass of sample (weight of the gel or absorbed water) after decantation of supernatant was measured. The WAI was calculated as grams of absorbed water per gram of dry sample mass $(1.25 \mathrm{~g})$ as illustrated in equation 6.

$$
W A I=\frac{\text { Weight gain of gel }(g)}{\text { Dryweight of extrudate }(g)}
$$

The clear supernatant of the sample obtained in analysis of WAI was weighed. Supernatant preserved during WAI measurement was evaporated at $105^{\circ} \mathrm{C}$ for four hours. The mass of dried solid as residual were measured. The WSI was calculated as a ratio of dry residue to the original mass (about $1.25 \mathrm{~g}$ ) used to estimate WAI and the result was expressed as percentage. See equation 7.

$$
\mathrm{WSI}=\frac{\mathrm{W}_{\mathrm{DS}}}{\mathrm{W}_{\mathrm{D}}(\mathrm{g})}
$$

Where: $W_{D S}$ : Weight of dry solids in supernatant; $W_{D}$ : Weight of extrudates

\section{RESULTS AND DISCUSSION}

\section{Water absorption and water solubility indices}

WAI has been used as a measure of quality attributes of extruded products and considered as indicators of the 


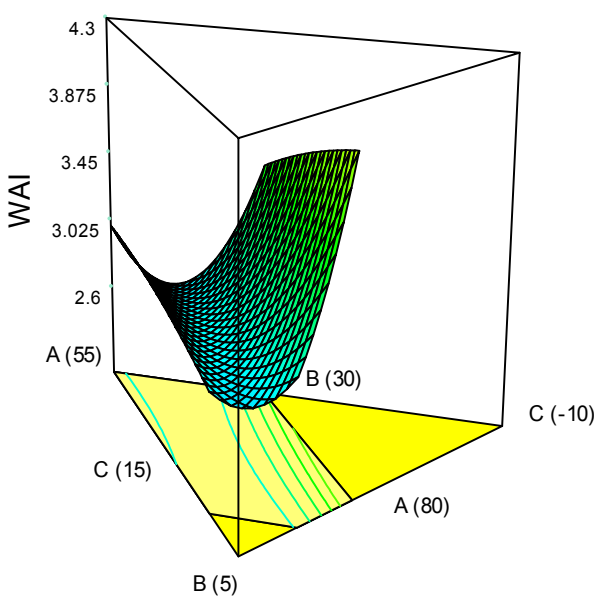

1

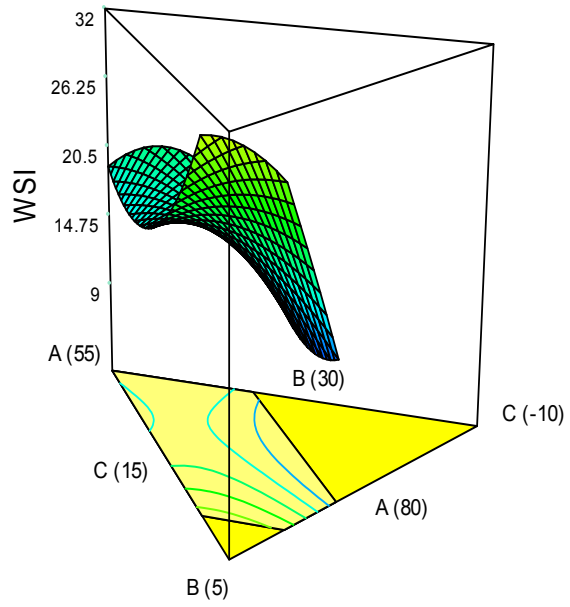

2

Figure 1. Response surface plots for WAI (1) and WSI(2) as a function of components at $21.43 \%$ moisture content, $77 \mathrm{~s}$ residence time and $125^{\circ} \mathrm{C}$ barrel temperature (A: MF, B: FFSF, C: MOLP)

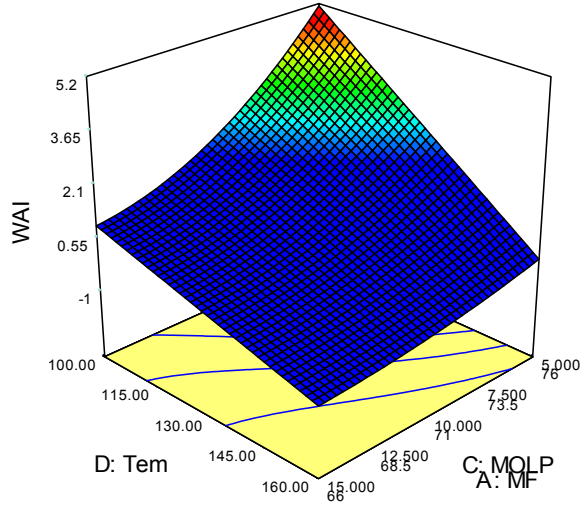

1

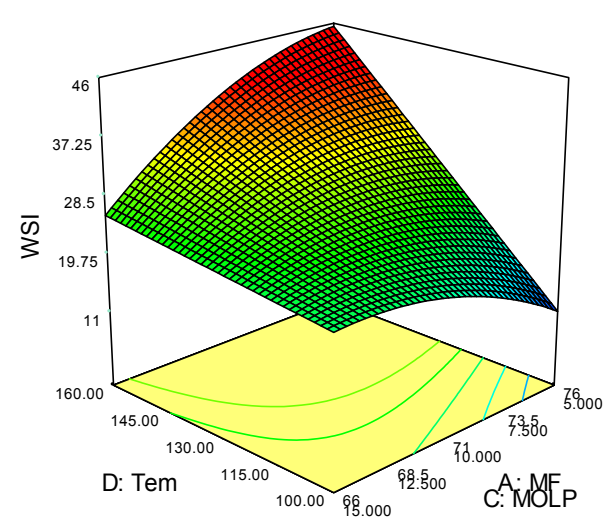

2

Figure 2. Response surface plots for WAI (1) and WSI (2) as a function of components at $15 \%$ moisture content, 60 s residence time and $19 \%$ FFSF

degree of starch gelatinization. On the other hand WSI can be used as an indicator for the degradation of molecular compounds and measures the degree of starch conversion during extrusion (Ding et al., 2006; Zhu et al., 2010). The values for WAl ranged between $2.02 \pm 0.04$ to $4.93 \pm 0.04 \mathrm{~g} / \mathrm{g}$ and the WSI varied from $9.46 \pm 1.11$ to $39.8 \pm 0.38 \mathrm{~g} / \mathrm{g}$ dry sample.

The response surface graph (Figure 1) shows that the maximum WAI value was found at lower temperature and lower value of MOLP in the blend. While lower values were observed at higher barrel temperature and higher level MOLP in a blend. MF was increased as
MOLP decreased in a blend, hence starch content increased as the fact that MF has higher starch content. WAI depends on availability of hydrophilic groups like starch materials which bind water molecules and lead to gel forming capacity of macromolecular. Eliasson (1983) studied on wheat-starch gluten mixtures reported that the lack of protein in raw materials could make starch gelatinization easier, since there is no material that can compete with starch in water absorption characteristic.

The surface response (Figure 2) shows that the higher WSI was obtained at higher barrel temperature and higher level of MF and lower level of MOLP. On the 


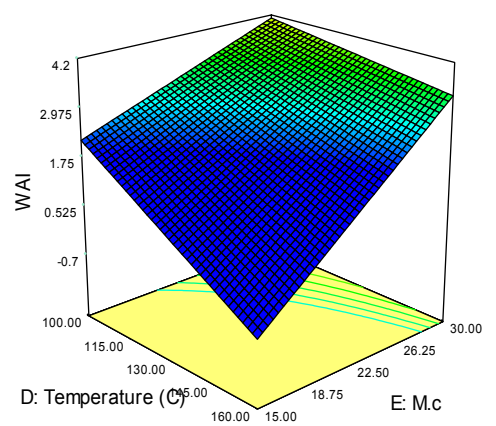

(1)

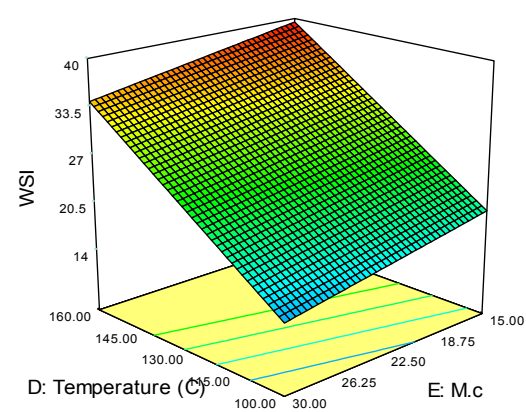

(2)

Figure 3. Response surface plots for $\mathrm{WAI}(1)$ and $\mathrm{WSI}(2)$ as a function of feed moisture content and temperature at and $71 \% \mathrm{MF}$, $19 \%$ FFSF, 10 MOLP and 77.14 s residence time and $19 \%$ FFSF.

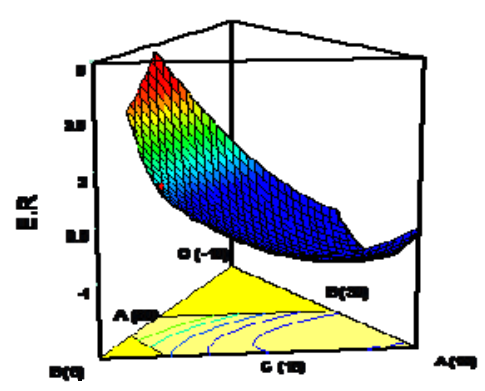

Figure 4. Response surface plots for ER as a function of components at $15 \%$ moisture content, 60 s residence time and $100^{\circ} \mathrm{C}$ Barrel Temperature (A: MF, B: FFSF, C: MOLP).

other hand the low WSI was observed at higher level of MOLP and low level of MF. This result indicates that, at higher temperature starch macromolecules are subjected to degradation resulted from extrusion cooking (Colonna et al 1989; Ding et al; 2005).

The feed moisture and temperature were found to have significant effect on the WAl as shown on Figure 3. Generally, WAI increased significantly as feed moisture increased from $15 \%$ to $30 \%$. At high moisture content, the viscosity of the starch would be low, allowing for extensive internal mixing and uniform heating which, in turn, would account for enhanced starch gelatinization (Lawton et al., 1972); it also may lead to increased water absorption. At higher temperature, WAI increased significantly as feed moisture increased. Similar change was observed at low temperature. WAI decreased as Temperature increased from $100^{\circ} \mathrm{C}$ to $160^{\circ} \mathrm{C}$. However, at higher feed moisture, there were no significant changes in WAI as a function of temperature. The result agreed with the report of Olletet al., (1999) and Ding et al., (2005). They explained that initial increase and subsequent decrease in WAI for the extruded products as temperature increased. At high moisture content, the viscosity of the starch would be low, allowing for extensive internal mix- ing and uniform heating which would account for enhanced starch gelatinization.

On the other hand, this study showed that WSI was significantly affected by barrel temperature and feed moisture content as shown on Figure 3. WSI increased significantly when the barrel temperature increased from $100^{\circ} \mathrm{C}$ to $160^{\circ} \mathrm{C}$. The effect of temperature was considerably higher when compared to that of feed moisture content. As feed moisture increased from $15 \%$ to $30 \%$, WSI decreased slightly. WSI indicates the extent of molecular degradation with the intensity of extrusion condition (Olletet al., 1999). Higher moisture content in extrusion process can diminish protein denaturation and starch degradation.

\section{Expansion ratio (ER)}

The experimental data on sectional expansion ratio ranged from 1.07 to $3.76\left(\mathrm{~mm}^{2}\right.$ sectional area of extrudate to sectional area of die), within to those reported for moringa-cereal-based extrudates (Liu et al., 2011). The response surface plots (Figure 4) illustrate the interaction of the effect of MF, MOLP and FFSF. The ER was found 


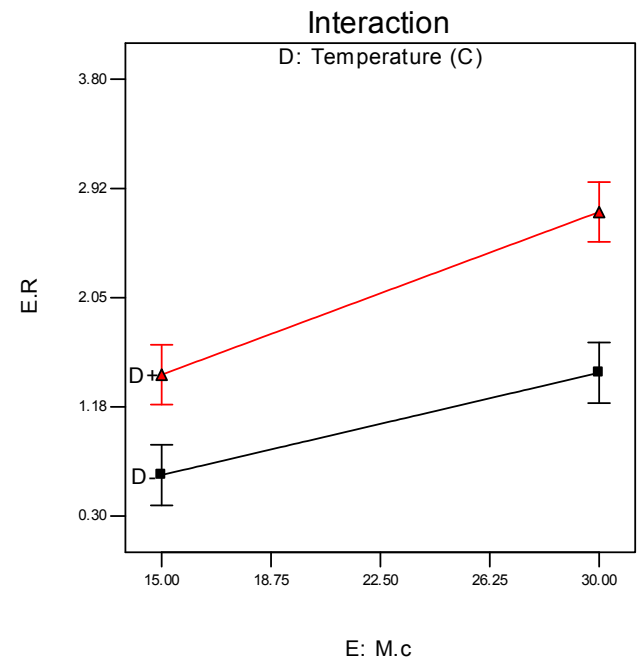

(1)

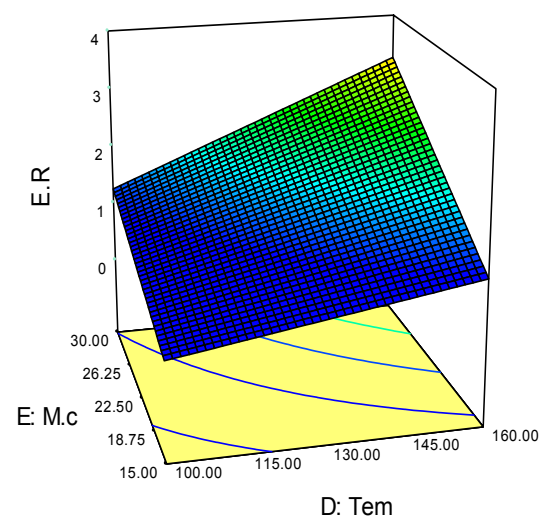

(2)

Figure 5. (1) Interaction graph of two dimension plot (2) Response surface plots for ER as a function of temperature and feed moisture content at 60 s residence time and $71 \%$ MF, 19\% FFSF, 10 MOLP.

to be most dependent on MF and MOLP content rather than FFSF content.

Higher MF and lower MOLP addition resulted to higher ER in the studied experimental range. The steady decrease in ER with increasing MOLP and FFSF could be due to the addition of increasing amounts of fibre and protein to the blend which may affect the extent of starch gelatinization and thus the rheological properties of the melted material in the extruder (Camire and King, 1991). The non-starch polysaccharides in fibre may bind water more tightly during extrusion than do protein and starch. This binding may inhibit water loss at the die and thus reduce expansion. Yanniotis, Petraki, and Soumpasi (2007) observed pectin reduces radial expansion by increasing the melt viscosity and reducing the availability of water for the gelatinization process.

The effects of temperature and moisture content were found to be dependent to each other (Figure 5). The ER was found to be higher at higher moisture content and higher temperatures. On the other hand decrease at low temperature and low moisture content. The response of expansion property on barrel temperature is relative to the saturated vapour pressure and viscosity of extrudate during extrusion. Pan, Zhang, \& Jane (1998) observed that when screw speed was high, low moisture and temperature resulted in less expanded product than other conditions which could be due to less water vapour pressure and viscosity developing during extrusion. It was observed that extrudate viscosity decreased with an increase of temperature. The decrease of the viscosity of the extruded dough would be beneficial to the generation of bubbles and lead to an increase in expansion (Ding et al., 2005).

\section{CONCLUSION}

In the present work, it has been demonstrated that extrusion cooking process significantly produced extruded starchy food fortified with FFSF and MOLP with desirable physical and chemical properties and suitable nutritional properties. Extrudates having various blending ratio of MF, FFSF and MOLP provided suitable physical and chemical properties such as higher ER, WAI and WSI and low water activity (aw). Increasing the MOLP level resulted in increased iron content. High processing temperature and low aw reduces the level of microbial activity on the extrudates. The sensory evaluation of extrudates suggests that extrusion of FFSF flour and MOLP in combination with maize flour can produce acceptable extruded snack which can be used as supplementary meal and subsequently help in combating micronutrient malnutrition for children and children bearing mothers.

\section{ACKNOWLEDGEMENT}

The authors thank Swedish International Development Cooperation Agency (Sida) for the financial support they provided to enable carrying out this research.

\section{REFERENCES}

Anderson RA, Conway HF, Pfeifer VF, Griffin EL(1969). Gelatinization of corn grits by roll and extrusion cooking. Cereal Science Today, 14, 4-12.

Camire ME, King CC(1991). Protein and fibre supplementation effects on extruded cornmeal snack quality. Journal of Food Science, 56, 760-763. 
Caprita R, Caprita A, Cretescu I(2010). "Protein Solubility as Quality Index for Processed Soybean". Animal Science and Biotechnologies, 43(1), 375-378.

Colonna P, Tayeb J, Mercier C(1989).Extrusion cooking of starch and starchy products.In C. Mercier, P. Linko, and J. M. Harper (Eds.).Extrusion cooking (pp. 247-320).American Association of Cereal Chemists, Inc.

Ding Q, Ainsworth P, Plunkett A, Tucker G, Marson H(2005). "The effect of extrusion conditions on the physicochemical properties and sensory characteristics of rice-based expanded snacks". Journal of Food Engineering, 73, 142-148.

Eliasson AC(1983). Differential, scanning calorimetry studies on wheat starch -gluten mixtures effect on gluten in gelatinisation of wheat starch. J. Cereal Sci., 11, 199-205.

Endres JG(2001), Soy protein products characteristics, nutritional aspect and utilization(Revised and expanded edition). USA, AOCS Press.

Fellows P(2000).Food Processing Technology, Principles and Practice, Cambridge, England, Woodhead Publishing Limited and CRC Press LLC.

Guy $R(2001)$. Extrusion cooking technologies and applications, WoodheadPublishing Limited.

Hernandez-Diaz JR, Quintero-Ramos A, Barnard J, BalandranQuintana RR (2007) Functional properties of extrudates prepared with blends of wheat flour/pinto bean meal with added wheat bran. Food Sci. and Technol. International, 13(4), 301-308.

Hsu R, Midcap S, Arbainsyah, De Witte L. (2006).Moringa oleifera; Medicinal and Socio-Economic Uses.International Course on Economic Botany. National Herbarium Leiden, the Netherlands.

Joshi $P$, Mehta $\mathrm{D}(2010)$. "Effect of dehydration on the nutritive value of drumstick leaves", Systems Biology, 1, 5 -9

Khan Y, Bhutta ZA(2010). Nutritional Deficiencies in the Developing World: Current Status and Opportunities for Intervention, Elsevier Inc.

Liu, k. (1999).Soybean chemistry, technology and utilization, (pp. 2528). New York: Aspen publisher

Liu S, Alavi S, Abughoush M(2011)."Extruded Moringa Leaf-Oat Flour Snacks: Physical, Nutritional, and Sensory Properties". International journal of food properties, Tylor and Francis Group LLC, 14(4), 854869

Malema BA(2006). Soybean production and utilisation in Tanzania, Dar es Salaam, DCD/MAFC, Tanzania.

NBS (Tanzania) \& ICF Macro.(2011). Tanzania Demographic and Health Survey 2010. Dar es Salaam, Tanzania: NBS and ICF Macro.
Oikonomou NA, Krokida MK(2012).Water absorption index and water solubility index prediction for extruded food products. International Journal of Food Properties, 15, 157-168.

Pan Z, Zhang S, Jane J(1998).Effect of extrusion variables and chemicals on the properties of starch-based binders and processing conditions. Cereal Chemistry, 75( 4), 541-546.

Price ML (2007). The moringa tree. Published 1985; Revised 2000 2002, 2007 by ECHO Staff, http://www.chenetwork.org/files pdf/Moringa.pdf , retrieved on $12^{\text {th }}$ July 2011

Riaz MN(Ed.), (2007). Extruders and Expanders in Pet Food, Aquatic and Livestock Feeds.Agrimedia $\mathrm{GmbH}$, Germany.

Shls ME, Shike M, Ross AC, Cabalero B, Robert JC(2005). Modern nutrition in health and disease, London, Lippincott Williams \& Wilkins, pp. 1780-1783.

Yanniotis S, Petraki A, Soumpasi E(2007). Effect of pectin and wheat fibers on quality attributes of extruded cornstarch. J. Food Engineering, 80, 594-599.

Zasypkin DV, Tung- Ching L (1998). Extrusion of Soybean and Wheat Flour as Affected by Moisture content. J. Food Sci., 63(6): 10581061.

Zhu L, Shukri R, de Mesa-Stonestreet NJ, Alavi S, Dogan H, Shi $Y(2010)$. "Mechanical and microstructural properties of soy protein high amylose corn starch extrudates in relation to physiochemical changes of starch during extrusion". J. Food Engineering, 100, 232 238.

How to cite this article: Leonard M.P. Rweyemamu, AthumaniYusuph, Godwill D. Mrema (2015). Physical properties of extruded snacks enriched with soybean and moringa leaf powder. Afr. J. Food Sci. Technol. 6(1):28-34 